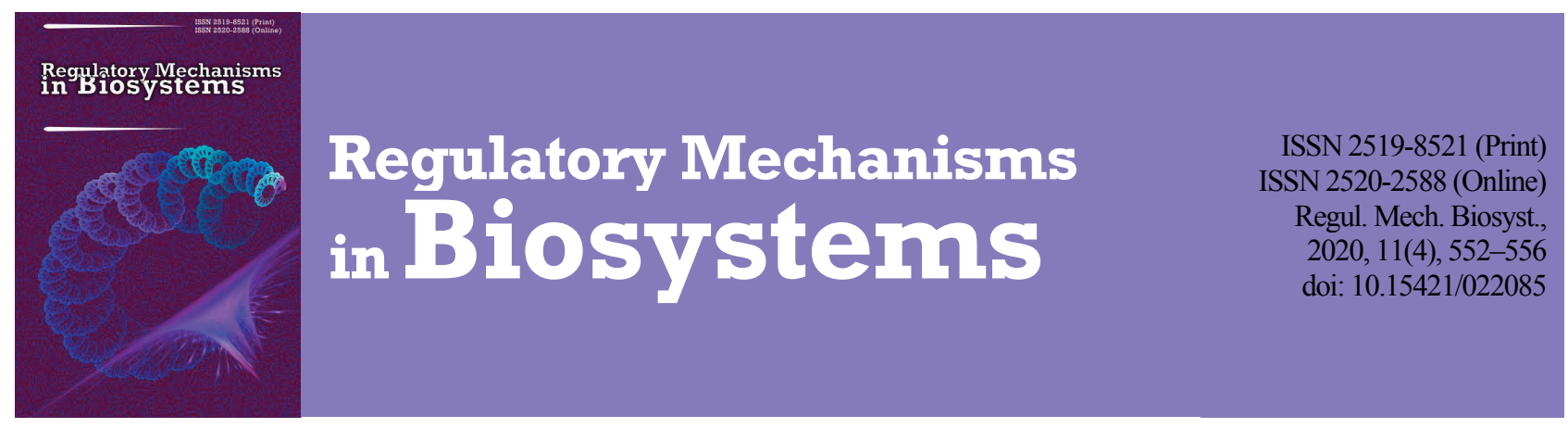

\title{
Microorganisms causing respiratory diseases in children in relation to age and diagnosis
}

\author{
H. O. Isaieva*, M. M. Mishyna*, M. O. Gonchar*, O. L. Logvinova*, M. A. Basiuk** \\ *Kharkiv National Medical University, Kharkiv, Ukraine \\ **Kharkiv Regional Children's Clinical Hospital, Kharkiv, Ukraine
}

Article info

Received 21.10.2020

Received in revised form 13.11.2020

Accepted 14.11.2020

Kharkiv National Medical University, Nauky Ave., 4, Kharkiv, 61022, Ukraine. Tel.: +38-098-005-90-12. E-mail:

anna1989isaeva@ukr.net

Kharkiv Regional

Children's Clinical

Hospital, Ozeryaanska st., 5 ,

Kharkiv, 61093, Ukraine.

Tel.: + 38-067-803-12-98.

E-mail:

basyk11maryanna@gmail.com

Isaieva, H. O., Mishyna, M. M., Gonchar, M. O., Logvinova, O. L., \& Basiuk, M. A. (2020). Microorganisms causing respiratory diseases in children in relation to age and diagnosis. Regulatory Mechanisms in Biosystems, 11(4), 552-556. doi:10.15421/022085

Community-acquired pneumonia (CAP) in children is still one of the leading causes of morbidity and mortality, especially in developing countries. The World Health Organization (WHO) has reported that pneumonia accounts for $15 \%$ of all deaths of children under 5 years old. The aim of the present study was to find out the predominance of microorganisms in the respiratory tract in children. 334 strains of microorganisms were isolated: Gram-positive - 293 strains, Gram-negative -41 . From the pharynx 183 strains were isolated, from the nose - 94, from sputum - 57. Among Gram-positive microorganisms the following were isolated: Staphylococcus aureus 44 strains of microorganisms, S. epidermidis - 75, Group A $\beta$-hemolytic streptococci - 39, viridans streptococci-55, Streptococcus pneumoniae - 34, Enterococcus faecalis - 2, Candida spp. - 38, Corynebacterium pseudodiphthericum - 6. Among Gram-negative microorganisms the following were isolated: Escherichia coli 4 strains of microorganisms, Klebsiella pneumoniae - 13, Pseudomonas aeruginosa - 6, Haemophilus influenzae - 11, Enterobacter cloacae - 7. Children were divided by age and diagnosis into four groups: I group - children with acute bronchitis ( $0-5$ years of age), II group - children with acute bronchitis ( $5-18$ years of age), III group - children with CAP ( $0-5$ years of age), IV group - children with CAP (5-18 years of age). Materials used in the research - nasal swabs, throat swabs and sputum. Microorganisms were isolated and identified using standard microbiological methods. $S$. aureus was the predominant microorganism isolate from the pharynx in children with bronchitis ( $0-5$ years). Group A $\beta$-hemolytic streptococci were isolated most often from the pharynx in children with bronchitis older than 5 years and in children with CAP less than 5 years of age. S. pneumoniae was most often isolated from the pharynx in children older than 5 years of age with CAP. S. aureus was the main microorganism, isolated from the nose in children with bronchitis in all age groups; in patients with CAP it was the predominant microorganism in children older than 5 years of age. $S$. aureus was the predominant microorganism, isolated from sputum in children with bronchitis older than 5 years. S. pneumoniae was the predominant microorganism, isolated from sputum in children with CAP older than 5 years. The research showed that $S$. pneumoniae is still one of the main pathogens that cause CAP in school aged children.

Keywords: children; pneumonia; Streptococcus pneumoniae; nasal swabs; pharyngeal swabs; induced sputum.

\section{Inroduction}

The respiratory system of the human organism is a reservoir for commensals and potential pathogenic microorganisms, that include Staphylococcus aureus, Streptococcus pneumoniae and Haemophilus influenzae, which compose the predominant part of respiratory tract microbiota (Robinson, 2004). The nose is the main reservoir of carrier state of S. aureus (Verhoeven et al., 2014), which can also be isolated in the pharynx (Mertz et al., 2009; Verhoeven et al., 2015). However, S. aureus is also a dangerous pathogen and one of the leading causes of communityacquired infections. Also $S$. aureus is an important microorganism that plays a significant role in the development of lung infections (Tong et al., 2015). S. aureus has a variety of surface proteins that recognize cellular adhesive molecules and can attach to them and penetrate into lung epithelial cells, which protects bacteria from the immune system of the host and cause chronic infection (Josse et al., 2017; Morgenea et al., 2018). Worldwide, some of the most clinically relevant bacteria involved in childhood respiratory diseases include $S$. pneumoniae, non-typable $H$. influenzae and S. aureus (O'Brien et al., 2009; Poll \& Opal, 2009; Navne et al., 2016). The etiology of pneumonia in the pediatric population can be classified by age-specific versus pathogen-specific organisms (Rudan et al., 2013). Neonates are at risk from bacterial pathogens present in the birth canal, and this includes organisms such as group B streptococci, Klebsiella sp., Escherichia coli (Al Hazzani et al., 2018; Arif, 2018; Chen et al., 2019). S. pneumoniae, S. pyogenes, and S. aureus can be identified in late-onset neonatal pneumonia (Arif, 2018; Ebeledike \& Ahmad, 2020). Viruses are the main cause of pneumonia in older infants and toddlers between 30 days and 2 years old (Verhoeven, 2019). The rise of cases related to $S$. pneumoniae and H. influenzae type B is observed in the age group 2 to 5 years old (Cutts et al., 2005; Gessner et al., 2005). $S$. pneumoniae is still the most commonly identified organism in children from 5 to 13 years old (GBD, 2016). Children with chronic diseases are also at risk for specific pathogens. In cystic fibrosis, pneumonia secondary to $S$. aureus and Pseudomonas aeruginosa is ubiquitous (Dryahina et al., 2016). Unvaccinated children are at risk for vaccine-preventable pathogens (Ebeledike \& Ahmad, 2020).

The incidence of respiratory infections peaks in childhood. Infection can be transmitted by asymptomatic carriers. Adherence of $S$. pyogenes to pharyngeal mucosal cells is a prerequisite to colonization or infection, and has been related to surface structures, such as lipoteichoic acid and fibronectin-binding proteins. Penetration or translocation of the organism through respiratory epithelial cells has been demonstrated for M-type 1 
S. pyogenes. If penetration of mucosal barriers occurs readily with these strains, it generally does not result in clinically detectable bacteremia in the vast majority of cases, since the incidence of invasive infection remains generally very low (O'Brien et al., 2002). Thus, the clearance of S. pyogenes by the human immune system must be highly efficient (Ferretti et al., 2016). Important members of the viridans streptococci that are normal commensals include Streptococcus mutans and S. sanguis, which are involved in the formation of dental caries, $S$. mitis which is associated with bacteremia, pneumonia, meningitis and periodontal disease. S. pyogenes is the leading cause of uncomplicated bacterial pharyngitis and tonsillitis. Indeed, only group A streptococci are sought routinely in cases of pharyngitis, although groups B, C, and G are sometimes identified. S. pyogenes infections can also result in sinusitis, otitis, and pneumonia with empyema (Baron \& Patterson, 1996). The aim of the present study was to detect the predominance of microorganisms in the respiratory tract in children, especially with CAP.

\section{Materials and methods}

Specimens were obtained from the nose, pharynx and sputum. Sputum production was induced by inhalation of $5.0 \%$ hypertonic saline solution, and the sputum sample was obtained by aspirating the nasopharynx through the nostrils or by expectoration if the child was old enough to produce an adequate sputum sample (Zar et al., 2003; Lahti et al., 2009). The study involved 100 children aged $0-18$ years with respiratory diseases: CAP (Order No.18 of 13.01.2005 "On approval of protocols for rendering medical aid to children in speciality "Children Pulmonology"), acute bronchitis, who were treated at Kharkiv Regional Children's Clinical Hospital in the intensive care unit, pulmonary department. Children were divided into four groups, according to Knobee et al. (2019), WHO: I group children with acute bronchitis 5 years old and less (17 children), II group children with acute bronchitis older than 5 years old (32 children), III group children with CAP 5 years old and less (19 children), IV group children with CAP older than 5 years old ( 32 children).

Bacterial cultures were performed according to standard microbiological methods. Isolation of $S$. aureus was on Mannitol Salt Agar and Yolk-Salt agar. For identification of $S$. aureus and S. epidermidis Staphy test 16 (Borno, $\mathrm{CZ}$ was used). Classic cultural methods (cultivation in 5\% $\mathrm{CO}_{2}$, colony morphology, Gram staining, catalase test, optochin sensitivity) were used to isolate S. pneumoniae (O'Brien et al., 2003; Satzke et al., 2013). For differentiation of Streptococci blood agar was used to detect types of hemolysis. Group A $\beta$-hemolytic streptococci isolates were identified by $\beta$-hemolysis, followed by Gram staining and catalase testing (Seale et al., 2016) and susceptibility to bacitracin. The cross-streaking with a strain of $S$. aureus on the blood agar was done to identify $H$. influenzae since the two species grow in symbiosis (Navne et al., 2016). For isolation and identification of $H$. influenzae Chocolate agar was used. Endo agar and ENTEROtest 24 (Borno, CZ) were used for isolation and identification of E. coli, K. pneumoniae. For isolation of Corynebacterium species tellurite blood agar and biochemical tests (cystinase test, urease test; fermentation of glucose, sucrose and starch) were used. For identification of $P$. aeruginosa NEFERMtest 24 was used (Borno, CZ). Sabouraud Dextrose Agar and Candidatest 21 (Borno, CZ) were used for isolation of Candida spp. from clinical specimens. CHROMagar TMOrientation (France) was used for isolation and differentiation of E. coli, K. pneumoniae, P. aeruginos, Enterococcus spp, S. aureus, S. epidermidis and Candida spp. Children were not given the pneumococcal vaccine.

The data were analysed using IBM SPSS 19 (USA). Data were presented as $95 \%$ confidence intervals with the Wilson Score method. The chi-square test was performed for comparison of microorganisms in the groups. Statistical significance was defined by $\mathrm{P}<0.05$.

\section{Results}

Overall, 51 of 100 children had CAP, 49 had acute bronchitis. 334 strains of microorganisms were isolated (Fig. 1), among them Grampositive - 293 (87.7\%), Gram-negative - 41 strains (12.3\%).

Among Gram-positive microorganisms the following strains were isolated (Fig. 2): 44 strains (13.2\%) of S. aureus, S. epidermidis -75 strains (22.4\%), Group A $\beta$-hemolytic streptococci - 39 strains (11.7\%), Viridans streptococci - 55 strains $(16.5 \%)$, S. pneumoniae - 34 strains (10.2\%), E. faecalis -2 strains ( $0.6 \%)$, Candida spp. -38 strains (11.3\%), C. pseudodiphthericum -6 strains $1.8 \%$.

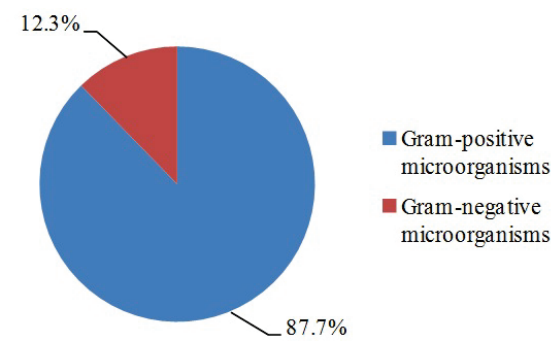

Fig. 1. Distribution of microorganisms isolated from children with respiratory diseases

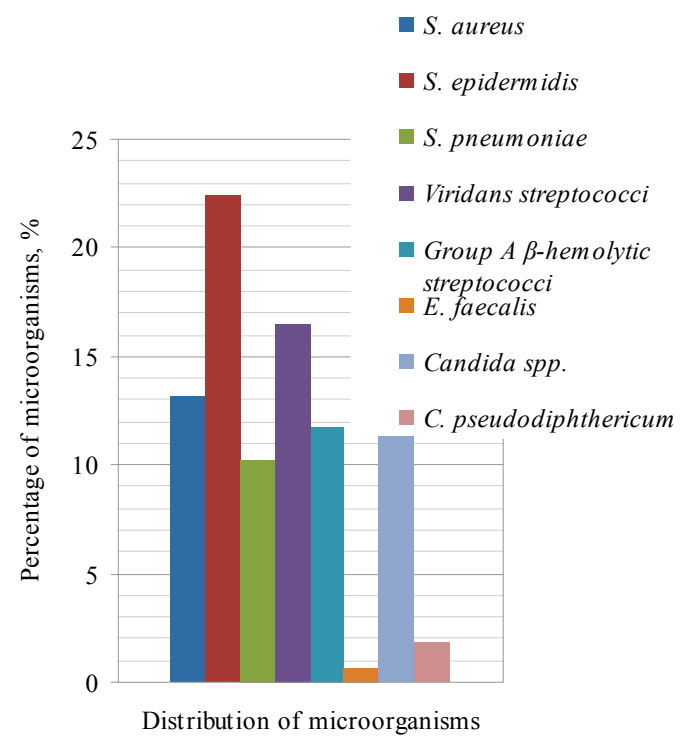

Fig. 2. Gram-positive microorganisms detected among children with respiratory tract infections

Among Gram-negative microorganisms the following strans were isolated (Fig. 3): E. coli -4 strains (1.2\%), K. pneumoniae - 13 strains (3.9\%), P. aeruginosa -6 strains $(1.8 \%), H$. influenzae - 11 strains $(3.3 \%)$. From E. cloacae 7 strains $(2.1 \%)$ were isolated.

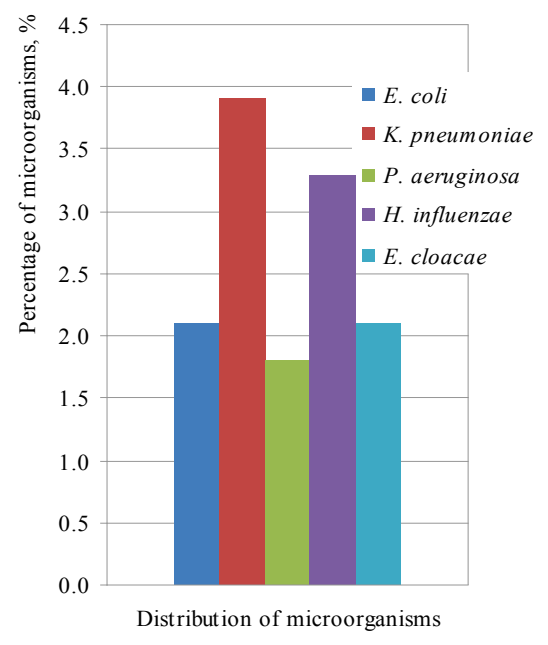

Fig. 3. Gram-negative microorganisms

detected among children with respiratory tract infections

Among 334 microorganisms, 183 strains (54.8\%) were isolated from the pharynx, from the nose -94 (28.1\%), from sputum -57 (17.1\%).

The majority of microorganisms isolated from the pharynx were Gram-positive. From S. aureus 20 strains were isolated with prevalence in 
the I group $-40.0 \%$, S. epidermidis - 14 strains with prevalence in the IV group $-42.9 \%$, Group A $\beta$-hemolytic streptococci -29 strains with prevalence in the II and in the III group (31.0\%). 23 strains were isolated from $S$. pneumoniae with significant prevalence in the IV group $\left(56.5 \%, \chi^{2}=\right.$ $12.30, \mathrm{P}=0.006$ ). Candida spp. were isolated 27 strains with prevalence in the IV group (37.0\%).

S. aureus $(\mathrm{n}=18)$ and $S$. epidermidis $(\mathrm{n}=59)$ were the most often detected pathogens isolated from the nose. S. aureus was prevalent in the I and in the II group (33.3\%). In the IV group we noted prevalence of S. epidermidis $\left(39.0 \%, \chi^{2}=9.95, \mathrm{P}=0.019\right)$.

Group A $\beta$-hemolytic streptococci $(\mathrm{n}=8)$, S. pneumoniae $(\mathrm{n}=10)$ and Candida spp. $(\mathrm{n}=11)$ were the most common pathogens isolated from sputum. Group A $\beta$-hemolytic streptococci were most often isolated in the II group $-50.0 \%$. S. pneumoniae was isolated with significant prevalence in the IV group $\left(90.0 \%, \chi^{2}=22.80, \mathrm{P}=0.00004\right)$. In the IV group we noted prevalence of Candida spp. $\left(63.6 \%, \chi^{2}=10.45, \mathrm{P}=0.015\right.$, Table 1$)$.

Table 1

Probability (\%) of microorganisms detection from different loci in each group $(95 \% \mathrm{Cl}) *$

\begin{tabular}{|c|c|c|c|c|}
\hline Microorganisms & I group** & II group & III group & IV group \\
\hline S. aureus*** & $40.0(21.9-61.3)$ & $25.0(11.2-46.9)$ & $5.7(1.1-24.6)$ & $25.0(11.2-46.9)$ \\
\hline S. aureus ${ }^{* * * *}$ & $33.3(16.3-56.3)$ & $33.3(16.3-56.3)$ & $11.1(3.1-32.8)$ & $22.2(9.0-45.2)$ \\
\hline S. epidermidis ${ }^{* * *}$ & $14.3(4.0-40.0)$ & $35.7(16.3-61.2)$ & $7.1(1.3-31.5)$ & $42.9(21.4-67.4)$ \\
\hline S. epidermidis**** & $17.0(9.5-28.5)$ & $30.5(20.3-43.2)$ & $13.6(7.0-24.5)$ & $39.0(27.6-51.7)$ \\
\hline Group A $\beta$-hemolytic streptococci*** & $17.2(7.6-34.6)$ & $31.0(17.3-49.2)$ & $31.0(17.3-49.2)$ & $20.7(9.9-38.4)$ \\
\hline Group A $\beta$-hemolytic streptococci***** & $12.5(2.2-47.1)$ & $50.0(21.5-78.5)$ & $12.5(2.2-47.1)$ & $25.0(7.2-59.1)$ \\
\hline S. pneumoniae ${ }^{* * *}$ & $13.0(4.5-32.1)$ & $13.0(4.5-32.1)$ & $17.4(7.0-37.1)$ & $56.5(36.8-74.4)$ \\
\hline S. pneumoniae p***** $^{*}$ & 0 & $10.0(1.8-40.4)$ & 0 & $90.0(59.6-98.2)$ \\
\hline Candida spp. $* * *$ & $14.8(5.9-32.5)$ & $22.2(10.6-40.8)$ & $25.9(13.2-44.7)$ & $37.0(21.5-55.8)$ \\
\hline Candida spp. ***** & $9.1(1.6-37.7)$ & $27.3(9.7-56.6)$ & 0 & $63.6(35.4-84.8)$ \\
\hline
\end{tabular}

Note: * - 95\% confidence interval with Wilson Score method; ** - I group - acute bronchitis, age 0-5 years; II group - acute bronchitis, age 5-18 years; III group - CAP, 0 5 years; IV group - CAP, 5-18 years; $* * *$ - microorganisms detection from pharynx; **** - microorganisms detection from nose; ***** - microorganisms detection from sputum.

In the IV group (children with CAP more than 5 years old) Candida spp. were the most common isolated pathogens. Candida spp. - normal mouth flora were not thought to be cause of upper respiratory tract disease, except in an immunocompromised host. Candida spp. usually not isolated from the lower respiratory tract (might originate in the oropharynx), can cause low respiratory tract disease in immunocompromised hosts. In the present study viridans streptococci were isolated $16.5 \%$ C. pseudodiphthericum $-1.8 \%$. Viridans group streptococci, Corynebacterium spp. are part of the normal upper respiratory tract flora and not thought to be a cause of respiratory tract disease. That is why the next step was comparison of the 6 main microorganisms associated with respiratory tract infections in each group. Among Gram-positive microorganisms we chose S. aureus, Group A $\beta$-hemolytic streptococci and $S$. pneumoniae. Among Gram-negative microorganisms we chose $K$. pneumoniae, $P$. aeruginosa and $H$. influen$z a e$, as most the important microorganisms.

In the I group, S. aureus (45.5\%) was the main microorganism, then Group A $\beta$-hemolytic streptococci - 24.2\%, K. pneumoniae - 15.2\%, S. pneumoniae $-9.1 \%, P$ aeruginosa and $H$. influenzae $-3.0 \%\left(\chi^{2}=\right.$ $26.09, \mathrm{P}=<0.001)$. In the II group the most often isolated pathogen was $S$. aureus $-41.0 \%$, then Group A $\beta$-hemolytic streptococci $-33.3 \%$, S. pneumoniae and $H$. influenzae $-10.3 \%$, K. pneumoniae $-5.1 \%\left(\chi^{2}=\right.$ $31.92, \mathrm{P}=<0.001)$. In the III group Group A $\beta$-hemolytic streptococci $(50.0 \%)$ were the most often isolated pathogens, next $S$. aureus and S. pneumoniae $-20.0 \%$, K pneumoniae and P. aeruginosa $-5.0 \%\left(\chi^{2}=\right.$ $20.20, \mathrm{P}=0.001)$. In the IV group the most often isolated pathogen was S. pneumoniae $-41.8 \%$, next $S$. aureus $-16.4 \%$, Group A $\beta$-hemolytic streptococci $-14.6 \%$, H. influenzae $-10.9 \%$, K. pneumoniae $-9.1 \%$, P. aeruginosa $-7.3 \%\left(\chi^{2}=26.93, \mathrm{P}=<0.001\right.$, Table 2$)$.

Table 2

Frequency of occurrence of microorganisms inside each group*

\begin{tabular}{lcccc}
\hline \multicolumn{1}{c}{ Microorganisms } & $\begin{array}{c}\text { Igroup*** } \\
\mathrm{n}=33\end{array}$ & $\begin{array}{c}\text { II group } \\
\mathrm{n}=39\end{array}$ & $\begin{array}{c}\text { III group } \\
\mathrm{n}=20\end{array}$ & $\begin{array}{c}\text { IV group } \\
\mathrm{n}=55\end{array}$ \\
\hline S. aureus & 15 & 16 & 4 & 9 \\
Group A $\beta$-hemolytic streptococci & 8 & 13 & 10 & 8 \\
S. pneumoniae & 3 & 4 & 4 & 23 \\
K. pneumoniae & 5 & 2 & 1 & 5 \\
P. aeruginosa & 1 & 0 & 1 & 4 \\
H. influenzae & 1 & 4 & 0 & 6 \\
\hline
\end{tabular}

Note: * - frequency allocation within each group was calculated with $\chi^{2} ; * *-\mathrm{I}$ IV groups see Table 1.

In the I group the prevalent microorganism isolated from the pharynx was $S$. aureus $-40.0 \%$, then Group A $\beta$-hemolytic streptococci $-25.0 \%$, K. pneumoniae $-20.0 \%$, S. pneumoniae $-15.0 \%\left(\chi^{2}=14.20, \mathrm{P}=0.014\right)$.
In the II group the leading microorganisms were Group A $\beta$-hemolytic streptococci - $42.9 \%$, then S. aureus - 23.8\%, S. pneumoniae - $14.3 \%$, K. pneumoniae and $H$. influenzae $-9.5 \%\left(\chi^{2}=14.14, \mathrm{P}=0.015\right)$. In the III group the prevalent microorganisms were Group A $\beta$-hemolytic streptococci $-53.0 \%$, next $S$. pneumoniae $-23.5 \%$, S. aureus $-11.8 \%$, K. pneumoniae and $P$. aeruginos $a-5.9 \%\left(\chi^{2}=19.35, \mathrm{P}=0.002\right)$. In the IV group the leading microorganism was $S$. pneumoniae $-41.9 \%$, next Group A $\beta$-hemolytic streptococci-19.4\%, S. aureus $-16.1 \%$, K. pneumoniae and $H$. influenzae $-9.7 \%$, P. aeruginosa $-3.2 \%\left(\chi^{2}=17.19, \mathrm{P}=\right.$ 0.004, Table 3).

The predominant microorganism isolated from the nose in the I group was $S$. aureus (54.6\%), then Group A $\beta$-hemolytic streptococci - $18.2 \%$, $K$. pneumoniae, $P$. aeruginosa and $H$. influenzae $-9.1 \%\left(\chi^{2}=12.45, \mathrm{P}=\right.$ $0.03)$. S. aureus was the predominant isolated from the nose in the II group (85.7\%), H. influenzae $-14.3 \%\left(\chi^{2}=24.71, \mathrm{P}=<0.001\right)$. S. aureus also was the predominant microorganism isolated from the nose in the IV group (66.7\%), followed by $S$. pneumoniae and K. pneumoniae $-16.7 \%$ $\left(\chi^{2}=12.00, \mathrm{P}=0.030\right)$.

\section{Table 3}

Frequency of occurrence of microorganisms from the pharynx inside each group*

\begin{tabular}{lcccc}
\hline \multicolumn{1}{c}{ Microorganisms } & $\begin{array}{c}\text { Igroup } \\
\mathrm{n}=20\end{array}$ & $\begin{array}{c}\text { II group } \\
\mathrm{n}=21\end{array}$ & $\begin{array}{c}\text { III group } \\
\mathrm{n}=17\end{array}$ & $\begin{array}{c}\text { IV group } \\
\mathrm{n}=31\end{array}$ \\
\hline S. aureus & 8 & 5 & 2 & 5 \\
Group A $\beta$-hemolytic streptococci & 5 & 9 & 9 & 6 \\
S. pneumoniae & 3 & 3 & 4 & 13 \\
K. pneumoniae & 4 & 2 & 1 & 3 \\
P. aeruginosa & 0 & 0 & 1 & 1 \\
H. influenzae & 0 & 2 & 0 & 3 \\
\hline
\end{tabular}

Note: I-IV groups see Table 1.

From sputum in the II group the prevalent microorganism was $S . a u$ reus $-45.5 \%$, followed by Group A $\beta$-hemolytic streptococci $-36.4 \%$, S. pneumoniae and $H$. influenzae $-9.1 \%\left(\chi^{2}=12.45, \mathrm{P}=0.030\right)$. From sputum in the IV group the main microorganisms were $S$. pneumoniae $50.0 \%, P$. aeruginosa and $H$. influenzae $-16.7 \%$, K. pneumoniae $-5.6 \%$ $\left(\chi^{2}=16.67, \mathrm{P}=0.005\right)$.

\section{Discussion}

The study detected that in children less than 5 years old with CAP which was confirmed in all cases, except one, by positive chest X-ray, the most common bacteria detected in the pharynx were Group A $\beta$-hemolytic streptococci (53.0\%), S. pneumoniae (23.5\%) and S. aureus (11.8\%). 
The most common bacterium detected from the nose in children less than 5 years old with CAP was $S$. aureus $(100 \%)$. The Pneumonia Etiology Research for Child Health Study Group (2019), which invstigated children under 5 years in Africa and Asia, revealed that in cases with a positive chest X-Ray in children under 5 years old with pneumonia, the most common bacteria detected in nasopharynx-oropharynx samples were S. pneumoniae (72.8\%), H. influenzae (57.8\%), and S. aureus (15.4\%).

$S$. aureus was the predominant microorganism isolated from the pharynx and nose in children 0-5 years old with bronchitis, which is similar to the findings of Tine et al. (2018), who investigating nose, throat swabs for PCR, found that $S$. aureus was the most frequent pathogen in the age group 1-5 years in children with acute respiratory tract infections.

Ning et al. (2017), who researched CAP among children under 5 years of age, analyzing nasal aspirates and sputum, revealed that S. aureus was identified in a small proportion of children with CAP in China, as in the present study, which shows that $S$. aureus was identified in a small proportion of children with CAP in the group of children under 5 years of age. In the current study $S$. aureus was the predominant microorganism isolated from the pharynx in children $0-5$ years of age with bronchitis, Group A $\beta$-hemolytic streptococci was predominant in children with CAP $0-5$ years of age, S. pneumoniae was predominant in children older than 5 years of age with CAP. This is opposite to findings of Knobee et al. (2019), who revealed that S. pneumoniae isolated from the oropharynx in children less than 5 years was associated with acute respiratory tract infections.

S. pneumoniae was the predominant microorganism, isolated from children with CAP older than 5 years, which corresponds to the British Thoracic Society guidelines for the management of community acquired pneumonia in children (2011) and Order No. 18 of 13.01.2005 "On approval of protocols for rendering medical aid to children in speciality "Children's Pulmonology"'. Prevalence of S. pneumoniae can be explained by the fact that due to Order No. 595 of 16.09.2011 "On the procedure for preventive vaccinations in Ukraine and quality control and circulation of medical immunobiological drugs", this type of vaccine in Ukraine is only recommended for children and elderly people. Therefore, preventive measures against $S$. pneumoniae - especially vaccination should be a priority.

Scientists from Europe, Don et al. (2005), who determined the aetiology of paediatric CAP in both ambulatory and hospitalized patients, found the most common microorganisms were M. pneumoniae (27\%) and S. pneumoniae (18\%). Their results confirm the role of S. pneumoniae in paediatric CAP at all ages. In the current study, S. pneumoniae was the most common pathogen in children with CAP older than 5 years old. Yadav \& Awasthi (2016) showed that there was sufficient data to show that $S$. pneumoniae and $H$. influenzae contribute to more than $50 \%$ cases of CAP in children under 5 years old in India. In the present study S. pneumoniae was the predominant microorganism in sputum of children older than 5 years old.

Ning et al. (2017) found that the most common pathogen in children with CAP less than 5 years of age was $S$. pneumoniae (5.2\%), while in the present study S. pneumoniae was the most common pathogen in children with $\mathrm{CAP}$, but older than 5 years of age.

Group A $\beta$-hemolytic streptococci were isolated most often in $0-5$ year old children with CAP from the pharynx. It can be explained as a carrier state of this microorganism. This finding is distinguished from the study of Delepech et al. (2017), who investigated throat swabs in children 5-13 years - asymptomatic carriers in Uganda, East-Central Africa and revealed that main age group was 8-10 year old children. High levels of Group A $\beta$-hemolytic streptococci in the group 0-5 year old children can be explained due to the attendance at kindergarten, formation of family clusters. Family clusters are uncommon, have typically two individuals, most often adults (DiPersio et al., 1996; Recco et al., 2002). Roy et al. (2003) discovered a family cluster of five cases of Group A $\beta$-hemolytic streptococci pneumonia. The potential reason for family clusters is prolonged contact between the index case and susceptible family members, virulence, host susceptibility. Prolonged close contact of individuals is a wellestablished risk factor for the spread of Group A $\beta$-hemolytic streptococci infection (Schwartz, 1992).
$H$. influenzae was the leading pathogen in group of children older than 5 years with CAP among Gram-negative microorganisms, even though those children were vaccinated against $H$. influenzae due to Order No. 595 of 16.09.2011 "On the procedure for preventive vaccinations in Ukraine and quality control and circulation of medical immunobiological drugs".

\section{Conclusion}

The present study revealed that Gram-positive microorganisms were detected more often compared with Gram-negative. Staphylococcus aureus, Streptococcus pneumoniae and Group A $\beta$-hemolytic streptococci were the major microorganisms. S. aureus was the most often isolated microorganism in children with bronchitis in all age groups. S. pneumoniae was the most often isolated pathogen in children with CAP older than 5 years of age. Group A $\beta$-hemolytic streptococci were the most often isolated pathogens in children with CAP in the age group $0-5$ years old. This finding requires further epidemiological research about vaccination coverage, attendance at preschool activities and school, formation of carrier state of family members and investigation of the area of living. In future research it is planned to detect sensitivity of the main microorganisms in biofilm form to antibacterial drugs in vitro.

I wish to acknowledge the help provided by personnel of the laboratory of the Kharkiv Regional Children's Clinical Hospital, Department of Pediatrics No. 1 and Neonatology and Department of Microbiology, Virology and Immunology named by D. P. Grynyov.

\section{References}

Al Hazzani, A. A., Bawazeer, R. A. B., \& Shehata, A. I. (2018). Epidemiological characterization of serotype group B Streptococci neonatal infections associated with interleukin-6 level as a sensitive parameter for the early diagnosis. Saudi Journal of Biological Science, 25(7), 1356-1364.

Arif, F. (2018). Updated recommendations of Rcog on prevention of early onset neonatal Group B Streptococcus infection. Journal of Ayub Medical College Abbottabad-Pakistan, 30(3), 490.

Baron, S., \& Patterson, M. J. (1996). Medical Microbiology. 4th edition. University of Texas Medical Branch, Galveston.

Chen, J. C., Jenkins-Marsh, S., Flenady, V., Ireland, S., May, M., Grimwood, K., \& Liley, H. G. (2019). Early-onset group B streptococcal disease in a risk factorbased prevention setting: A 15-year population-based study. The Australian and New Zealand Journal of Obstetrics and Gynaecology, 59(3), 422-429.

Cutts, F. T., Zaman, S. M., Enwere, G., Jaffar, S., Levine, O. S., Okoko, J. B., Oluwalana, C., Vaughan, A., Obaro, S. K., Leach, A., McAdam, K. P., Biney, E., Saaka, M., Onwuchekwa, U., Yallop, F., Pierce, N. F., Greenwood, B. M., Adegbola, R. A., \& Gambian Pneumococcal Vaccine Trial Group (2005). Efficacy of nine-valent pneumococcal conjugate vaccine against pneumonia and invasive pneumococcal disease in The Gambia: Randomised, double-blind, placebo-controlled trial. The Lancet, 365(9465), 1139-1146.

Delpech, G., Sparo, M., Baldaccini, B., Pourcel, G., Lissarrague, S., \& Allende, L. G. (2017). Throat carriage rate and antimicrobial resistance of Streptococcus pyogenes in rural children in Argentina. Journal of Preventive Medicine and Public health, 50(2), 127-132.

DiPersio, J. R., File Jr., T. M., Stevens, D. L., Gardner, W. G., Petropoulos, G., \& Dinsa, K. (1996). Spread of serious disease-producing M3 clones of group A Streptococcus among family members and health care workers. Clinical Infectious Diseases, 22(3), 490-495.

Don, M., Fasoli, L., Paldanius, M., Vainionpaa, R., Kleemola, M., Raty, R., Leinonen, M., Korppi, M., Tenore, A., \& Canciani, M. (2005). Aetiology of community-acquired pneumonia: Serological results of a paediatric survey. Scandinavian Journal of Infectious Diseases, 37, 806-812.

Dryahina, K., Sovova, K., Nemec, A., \& Spanel, P. (2016). Differentiation of pulmonary bacterial pathogens in cystic fibrosis by volatile metabolites emitted by their in vitro cultures: Pseudomonas aeruginosa, Staphylococcus aureus, Stenotrophomonas maltophilia and the Burkholderia cepacia complex. Journal of Breath Research, 10(3), 037102.

Ferretti, J. J., Stevens, D. L., \& Fischetti, V. A. (2016). Streptococcus pyogenes: Basic biology to clinical manifestations. University of Oklahoma Health Sciences Center, Oklahoma City.

GBD 2016 Lower Respiratory Infections Collaborators (2018). Estimates of the global, regional, and national morbidity, mortality, and aetiologies of lower respiratory infections in 195 countries, 1990-2016: A systematic analysis for the 
Global Burden of Disease Study 2016. The Lancet Infectious Diseases, 18(11) $1191-1210$.

Gessner, B. D., Sutanto, A., Linehan, M., Djelantik, I. G., Fletcher, T., Gerudug, I. K. Ingerani Mercer, D., Moniaga, V., Moulton, L. H., Moulton, L. H., Mulholland, K., Nelson, C., Soemohardjo, S., Steinhoff, M., Widjaya, A., Stoeckel, P., Maynard, J., \& Arjoso, S. (2005). Incidences of vaccine-preventable Haemophilus influenzae type $b$ pneumonia and meningitis in Indonesian children: Hamletrandomised vaccine-probe trial. The Lancet, 365(9453), 43-52.

Harris, M., Clark, J., Coote, N., Fletcher, P., Harnden, A., McCean, M., Thomas, A. \& British Thoracic Society Standards of Care Committee (2011). British Thoracic Society guidelines for the management of community acquired pneumonia in children: Update 2011. Thorax, 66(2), 1-23.

Josse, J., Laurent, F., \& Diot, A. (2017). Staphylococcal adhesion and host cell invasion: Fibronectin-binding and other mechanisms. Frontiers in Microbiology, 8, 2433.

Knobee, R. B., Diallo, A., Fall, A., Gueye, A. D., Dieng, A., D van Immerzeel, T., Ba, A., Diop, A., Diop, A., Niang, M., \& Boye, C. S. B. (2019). Pathogens causing respiratory tract infections in children less than 5 years of age in Senegal. Microbiology Insights, 12, 1-8.

Lahti, E., Peltola, V., Waris, M., Virkki, R., Rantakokko-Jalava, K., Jalava, J., Eerola, E., \& Ruuskanen, O. (2009). Induced sputum in the diagnosis of childhood community-acquired pneumonia. Thorax, 64(3), 252-257.

Mertz, D., Frei, R., Periat, N., Zimmerli, M., Battegay, M., Flückiger, U., \& Widmer, A. F. (2009). Exclusive Staphylococcus aureus throat carriage: At-risk populations. Archieves of Internal Medicine, 169(2), 172-178.

Morgenea, M. F., Botelho-Neversa, E., Grattarda, F., Pilleta, S., Berthelota, P., Pozzettoa, B., \& Verhoeven, P. O. (2018). Staphylococcus aureus colonization and non-influenza respiratory viruses: Interactions and synergism mechanisms. Virulence, 9(1), 1354-1363.

Navne, J. E., Borresen, M. L., Slotved, H. C., Andersson, M., Melbye, M., Ladefoged, K., \& Koch, A. (2016). Nasopharyngeal bacterial carriage in young children in Greenland: A population at high risk of respiratory infections 2016. Epidemiology and Infection, 144(15), 3226-3236.

Ning, G., Wang, X., Wu, D., Yin, Z., Li, Y., Wang, H., \& Yang, W. (2017). The etiology of community-acquired pneumonia among children under 5 years of age in mainland China, 2001-2015: A systematic review. Human Vaccines and Immunotherapeutics, 13(11), 2742-2750.

O’Brien, K. L., Beall, B., Barrett, N. L., Ciselak, P. R., Reingold, A., Farley, M. M., Danila, R., Zell, E. R., Facklam, R., Schwartz, B., Schuchat, A., \& Active Bacterial Core Surveillance/Emrging Infections Program Network (2002). Epidemiology of invasive group A Streptococcus disease in the United States, 19951999. Clinical Infectious Diseases, 35, 268-276.

O’Brien, K. L., Nohynek, H., \& World Health Organization Pneumococcal Vaccine Trials Carriage Working Group (2003). Report from a WHO Working Group: Standard method for detecting upper respiratory carriage of Streptococcus pneumoniae. The Pediatric Infectious Disease Journal, 22(2), 1-11.

O’Brien, K. L., Wolfson, L. J., Watt, J. P., Henkle, E., Deloria-Knoll, M., McCall, N., Lee, E., Mulholland, K., Levine, O. S., Cherian, T., Hib \& Pneumococcal Global Burden of Disease Study team (2009). Burden of disease caused by Streptococcus pneumoniae in children younger than 5 years: Global estimates. The Lancet, 374, 893-902.

Recco, R. A., Zaman, M. M., Cortes, H., Colucci, J., Poomkudy, G., \& Kaplan, E. L. (2002). Intra-familial transmission of life-threatening group $A$ streptococcal infection. Epidemiology and Infection, 129(2), 303-306.

Robinson, J. (2004). Colonization and infection of the respiratory tract: What do we know? Paediatrics and Child Health, 9(1), 21-24
Roy, S., Kaplan, E. L., Rodriguez, B., Schreiber, J. R., Salata, R. A., Palavecino, E. $\&$ John, C. C. (2003). A family cluster of five cases of Group $A$ streptococcal pneumonia. Pediatrics, 112(1), 61-65.

Rudan, I., O’Brien, K. L., Nair, H., Liu, L., Theodoratou, E., Qazi, S., Lukšić, I, Fischer Walker, C. L., Black, R. E., Campbell, H., \& Child Health Epidemiology Reference Group (2013). Epidemiology and etiology of childhood pneumonia in 2010: Estimates of incidence, severe morbidity, mortality, underlying risk factors and causative pathogens for 192 countries. Journal of Global Health, 3(1), 010401.

Satzke, C., Turner, P., Virolainen-Julkunen, A., Adrian, P. V., Antonio, M., Hare K. M., Henao-Restrepo, A. M., Leach, A. J., Klugman, K. P., Porter, B. D., SáLeão, R., Scott, J. A., Nohynek, H., O’Brien, K. L., \& WHO Pneumococcal Carriage Working Group (2013). Standard method for detecting upper respiratory carriage of Streptococcus pneumoniae: Updated recommendations from the World Health Organization Pneumococcal Carriage Working Group. Vaccine, 32(1), 165-179.

Schwartz, B., Elliott, J. A., Butler, J. C., Simon, P. A., Jameson, B. L., Welch, G. E., $\&$ Facklam, R. R. (1992). Clusters of invasive group $A$ streptococcal infections in family, hospital, and nursing home settings. Clinical Infectious Diseases, $15(2), 277-284$

Seale, A. C., Davies, M. R., Anampiu, K., Morpeth, S. C., Nyongesa, S., Mwarumba, S., Smeesters, P. R., Efstratiou, A., Karugutu, R., Mturi, N., Williams, T. N., Scott, J. A. G., Kariuki, S., Dougan, G., \& Berkley, J. A. (2016). Invasive group A Streptococcus infection among children, Rural Kenya. Emerging Infectious Diseases, 22(2), 224-232.

The Pneumonia Etiology Research for Child Health Study Group (2019). Causes of severe pneumonia requiring hospital admission in children without HIV infection from Africa and Asia: The PERCH multi-country case-control study. The Lancet, 394(10200), 757-779.

Tine, R. C., Ndiaye, L. A., Niang, M. N., Kiori, D. E., Dia, N., Gaye, O., \& Broutin, H. (2018). Upper respiratory infections in a rural area with reduced malaria transmission in Senegal: A pathogens community study. BMC Infectious Diseases, $18,459$.

Tong, S. Y. C., Davis, J. S., Eichenberger, E., Holland, T. L., \& Fowler Jr., V. G. (2015). Staphylococcus aureus infections: Epidemiology, pathophysiology, clinical manifestations, and management. Clinical Microbiology Reviews, 28(3), 603-661.

Van der Poll, T., \& Opal, S. M. (2009). Pathogenesis, treatment, a6nd prevention of pneumococcal pneumonia. The Lancet, 374(9700), 1543-1556.

Verhoeven, D. (2019). Influence of immunological maturity on respiratory syncytial virus-induced morbidity in young children. Viral Immunology, 32(2), 76-83.

Verhoeven, P. O., Gagnaire, J., Botelho-Nevers, E., Grattard, F., Carricajo, A., Lucht, F., Pozzetto, B., \& Berthelot, P. (2014). Detection and clinical relevance of Staphylococcus aureus nasal carriage: An update. Expert Review of Anti-Infective Therapy, 12(1), 75-89.

Verhoeven, P. O., Haddar, C. H., Grattard, F., Carricajo, A., Botelho-Nevers, E., Poz zetto, B., \& Berthelot, P. (2015). Does pharyngeal sampling improve the detection of nasopharyngeal persistent carriers of Staphylococcus aureus? Journal of Infection, 70(5), 549-552.

Yadav, K. K., \& Awasthi, S. (2016). The current status of community-acquired pneumonia management and prevention in children under 5 years of age in India: A review. Therapeutic Advances in Infectious Disease, 3(3-4), 83-97.

Zar, H. J., Tannenbaum, E., Hanslo, D., \& Hussey, G. (2003). Sputum induction as a diagnostic tool for community-acquired pneumonia in infants and young children from a high HIV prevalence area. Pediatric Pulmonology, 36(1), 58-62. 